\title{
How male Jordanian Psychiatric Nurses became Regular Smokers at University: Lessons in Tolerance, Cultural Identity and Stress Reduction
}

\author{
Khaldoun M. Aldiabat ${ }^{1, *}$, Michael Clinton ${ }^{2}$ \\ ${ }^{1}$ School of Nursing, University of Northern British Columbia, 3333 University Way, Prince George- BC, V2N 4Z9, Canada \\ ${ }^{2}$ Rafic Hariri School of Nursing, American University of Beirut, Riad El-Solh, Beirut 1107 2020, Lebanon \\ *Corresponding Author: aldiabat@unbc.ca
}

Copyright (C) 2013 Horizon Research Publishing All rights reserved.

\begin{abstract}
This paper presents smoking experience of Jordanian psychiatric nurses (JSNs) when they were nursing students and how the contextual factors in Jordanian universities and faculties of nursing influenced their smoking behaviours to become regular smokers. Background: Smoking is endemic in Jordan especially among male nursing students despite their awareness of its harmful effects. Smoking is a risk factor for the students themselves, and for their future patients. A better understanding of how male Jordanian psychiatric nurses became regular smokers when they were students is needed if smoking reduction programs and smoking cessation programs are to be effective in reducing smoking in Jordanian psychiatric hospitals and faculties of nursing. Aim: To explore retrospectively how male JPNs became regular smokers when they were studying nursing. Method: A classical grounded theory study of eight male psychiatric nurses employed in Amman was conducted to better understand why smoking is endemic among them and how they contextualized smoking into their lives to be regular smokers. Findings: Becoming regular smokers is the basic psychological process that explains how male Jordanian psychiatric nurses integrate smoking into their lives. Jordanian universities and faculties of nursing play a paradoxical role in socializing male nursing students into regular smoking behaviours while at the same time instructing them about the importance of health promotion and patient education. As a result, male nursing students learn to become regular smokers, but not how to assist themselves or their patients to cope with stress in less harmful ways. Five contextual factors influence male Jordanian nursing students to transition from occasional to regular smoking: the stressful demands of university nursing programs; encouragement to smoke from other students; lax enforcement of university non-smoking policies; no access to smoking reduction programs or smoking cessation programs; and gaps in nursing curricula. Conclusion: There are contextual and cultural factors in Jordanian universities
\end{abstract}

and faculties of nursing that result in male nursing students becoming regular smokers. The findings reported here make the case for smoking prevention programs and smoking cessation program in Jordanian universities. They are particularly relevant to university administrations, nursing faculty, and health promotion specialists.

Keywords Male Jordanian Nursing Students, Grounded Theory, Smoking Behaviours, Smoking Reduction, Smoking Cessation

\section{Aim}

Smoking is on the increase in countries of the Eastern Mediterranean region including Jordan (World Health Organization [WHO], 1997). In 2002, the Center for Disease Control and Prevention (CDC) reported that the prevalence of smoking among Jordanian men aged 18 years or older was $51 \%$ compared to that of $8 \%$ for Jordanian women of the same age. On average, Jordanian men were found to smoke 23 cigarettes per day compared with the 12 cigarettes per day reported by Jordanian women. These smoking prevalence rates reflect the demographic structure of Jordan, where $60 \%$ of the population is aged between 18 and 64 years (Jordan Department of Statistics, 2006). The Jordanian Department of Statistics (2002) attributes significant morbidity and morbidity to smoking. "Cardiovascular diseases are responsible for around $42 \%$ of all deaths in Jordan and cancer accounts for a further $13 \%$ of deaths. Smoking is the main factor contributing to both health problems" (Ma'ayeh, 2003, p. 3). As in other countries, lung cancer mortality rates among smokers and previous smokers in Jordan have been associated with smoking (Kofahi \& Haddad, 2005).

The transition period from high school to university is a critical developmental period for adolescents and young adults. The period is characterized by physiological and 
psychological changes that put students at risk for unhealthy behaviours, including smoking (Mansour, Halabi, \& Dawani, 2009). The university period is critical because it is a time when smoking the occasional cigarette as an experiment develops into a regular smoking habit (Hammond, Tremblay, Chaiton, Lessard, \& Callard, 2005).

In Jordan, smoking cigarettes at university represents one of the most significant public health problems that affects young adults. The estimated prevalence of smoking among Jordanian university students is nearly thirty per cent $(28.6 \%)$. Of the students who report smoking, almost half (42.5\%) had made no attempt to stop smoking; and almost a third (30.6\%) do not intend to stop (Haddad \& Malak, 2002).

In a later study, the smoking prevalence rate among Jordanian university students was reported as $35 \%$; with a gender specific rate of $56.9 \%$ for males and $11.4 \%$ for females. Of the students who smoked, $85.5 \%$ began smoking cigarettes at or around the age of 15 years (Khader \& Alsadi, 2008).

The prevalence of smoking among students in faculties of nursing varies by country. A study conducted in Israel reported a smoking prevalence rate of 21.7\% (Baron-Epel, Josephsohn, \& Ehrenfeld, 2004). An Australian study found that the smoking rate among undergraduate nursing students was $24.1 \%$ ( Clark, McCann, Rowe, \& Lazenbatt, 2004). A higher prevalence of smoking has been reported for male Japanese nursing students (52.4\%) (Suzuki, Ohida, Yokoyama, Kaneita, \& Takemura, 2005). Durkin (2007) has summarized the many factors that influence nursing students to commence or continue smoking during college nursing programs: " peer group influence, emotional distress, having friends who smoke, living alone, stress and image, tension relief, relaxation, and craving" (p.152).

Investigating smoking behaviours among nursing students is important because nurses can play a significant role in promoting health, and preventing diseases related to smoking (Clark, McCann, Rowe, \& Lazenbatt, 2004). Furthermore, nursing students' future commitment to promoting smoking cessation may be compromised by their own smoking behaviours (Smith, 2007).

While many researchers worldwide have investigated tobacco smoking among nursing students, no previous qualitative studies could be found on this topic. Therefore, little is known about the psychosocial processes through which contextual factors influence the smoking behaviours of nursing students, or about how faculties of nursing inadvertently shape the short-term and long-term smoking behaviours of psychiatric nurses. Moreover, there are no previous qualitative studies of how regular smoking behaviours are developed during attendance at faculties of nursing in countries with high smoking prevalence rates.

The purpose of the research study reported here was to deepen the discussion of the psychosocial processes involved in becoming a regular smoker. The wider study investigated how Jordanian psychiatric nurses contextualize and integrate smoking behaviours into their lives. Here we describe the contextual factors associated with life as a university nursing student that play a significant role in establishing regular smoking behaviours. Our study findings are important for three reasons:

1. The high prevalence of smoking among Jordanian psychiatric nurses is of concern due to the health risks involved for both nurses and patients.

2. Faculties of nursing are an important influence on the smoking behaviours of male Jordanian nurses and could do more to protect the health of students.

3. The contextual factors that influence smoking behaviours among Jordanian psychiatric nurses are relevant to understanding how cultural and other factors encourage the transition from occasional to regular smoking during the formative years of university education.

\section{Method}

Our investigation of the smoking behaviours of male Jordanian psychiatric nurses used a classical grounded theory approach (Glaser \& Strauss, 1967; Aldiabat \& Clinton, 2012). The study was conducted in Amman, Jordan in 2009-2010. Research ethics committees in Canada and Jordan approved the study. Data were collected from a theoretical sample of eight male psychiatric nurse smokers employed at a psychiatric hospital. Semi-structured interviews and non-participant observation were used to collect the data. Data that will be presented in this paper based on what JNPs retrospectively recall about their smoking experience when they were nursing students. The constant comparative method was used to analyze the data. Data collection, coding and analysis occurred simultaneously. Data analysis was closely monitored to ensure trustworthiness by ensuring credibility, transferability, dependability and confirmability (Lincoln \& Guba, 1985).

\section{Becoming a regular smoker at university}

According to the accounts given by the eight male psychiatric nurse participants in our study, the transition to regular smoking at university involves five sets of contextual factors that we conceptualized as sub-categories of contextualizing smoking behaviours over time, the basic psychological process that describes how male Jordanian psychiatric nurses integrate regular smoking into their lives:

1. The stressful demands of nursing programs

2. Encouragement to smoke from other nursing students

3. Lax enforcement of university non-smoking policies

4. No access to smoking reduction or cessation programs.

5. Gaps in nursing curricula.

When considering the transition from occasional smoker to regular smoker at university, it is important to take into account two interrelated developmental transitions that influence the process: the first, and more general, is the transition from adolescence to adulthood; the second is the more specific transition from the role of high school student 
to that of university student. It is not possible in a grounded theory study to delineate which aspect of transition, general or specific, is the more relevant when explaining how contextual factors influence male Jordanian nursing students to become regular smokers. However, it is possible to depict what happens when these transitions combine to influence behaviour. One participant said:

.... I laugh when I remember that period of my life. Even [now] after my long nursing experience, I cannot understand and describe what happened during that time.... Nothing was clear to me. I mean, that my thinking was a mixture of high school thinking and the thinking of a mature university student... I found it hard to shed completely my high school thinking and take on the role of a university student. It took time to become familiar with the new environment, the new teaching style and course requirements.... I had another burden on my shoulders - I was in a very early stage of adulthood, but the others expected me to behave like a mature man.... Actually, I wanted others to treat me like an adult, but their expectations exceeded my abilities at the time... I did not realize these problems then, but now I know they stressed me and increased my smoking (Aladdin).

Another participant reported how moving away from his parents and the conservative community where he had lived, combined with an increase in discretionary spending, supported his transition to regular smoking:

Although studying nursing was not my choice, I was so excited to study at the university because I would get some freedom and live a new life far away from life in the country. The university was located in the city a long way from where my family lived. I moved into a shared student residence with a group of university guys .... We were six guys; four of us were smokers; the other two guys learned smoking one term before they graduated from the university.... During that time, I noticed that my smoking rate had increased and become regular. Before that, I was smoking occasionally or when others offered me cigarettes. I smoked no more than 10 cigarettes a week. Then I started to buy my own cigarettes (one packet every three days) and rarely borrowed them from those around me. No longer did I feel guilty about smoking.... My parents were sending me extra money monthly for rent and other life expenses. I used some to buy cigarettes... Only my Mum knew that I smoked and she kept that top secret between me and her... She worked on my Dad to get extra pocket money for me.... When Dad asked me why I needed this money; I said something about high living expenses in the city...(Kamal)

Gender identity is a factor in explaining such collusion. The transitions from adolescence to adulthood, and from high school to university, involve significant sensitivity to gender identity; which takes on added importance as males transition into nursing. In Arab countries, nursing is regarded as a career for women only - with all the implications this has for running counter to male cultural stereotypes. Consider this comment from a participant:

I studied nursing during the late 1980s. You know, during that time few males were studying nursing in Jordan...It was, like, a purely female nursing faculty [females were in the majority] .... As a Middle Eastern male, I was anxious not to lose my manhood in the eyes of society.... Hence, I decided to keep my moustache and beard long and to smoke (...) This was to keep my male image intact in the minds of others (Hassan)

The change from occasional smoker to regular smoker is influenced by contextually specific factors associated with the transition from adolescence to adulthood combined with the transition from high school student to university student, associated with the greater freedom university life provides and culturally expected gender stereotypes.

\section{Stressful Demands of Nursing Programs}

Five of the eight participants stated that the four year Bachelor of Nursing programs in Jordan have high standards and numerous requirements that exhaust students and put them under considerable psychological stress. From the perspective of the participants, the stressors are:

- Comprehensive time limited curricula.

- Miscommunication between faculties that results in non-nursing faculties increasing or decreasing expectations of nursing students without reference to either the nursing curriculum or to the role of the graduate nurse.

- Perceived excessive use of clinical report writing, preparation of care plans, written assignments, examinations, and student classroom presentations.

- $\quad$ Significant gaps between what nursing students have been taught at university and the realities of nursing practice in clinical settings.

- Lack of learning resources in clinical settings.

- Poor communication among nursing students, professors and clinical instructors.

One way the participants coped with these stressors was by smoking more cigarettes. One participant said:

Before I entered the nursing program, I 
thought nursing would be an easy program, but I was completely wrong. I found nursing to be a very challenging specialty.... Actually, it was easy to read the material and understand it, the difficulty was how to think in a critical way, how to solve problems, and how to apply the nursing process comprehensively.... From my perspective, nursing is a multidimensional specialty... I mean, you need to study courses from different specialties such as sociology, anatomy, pharmacology... as prerequisites. Professors of the courses outside nursing do not know exactly what nursing students need to learn. For example, as a nurse I do not think it was a good idea to study statistics from a mathematical perspective instead of a bio-statistical perspective. I think if the minimum period of study was longer such as five years instead of four, our understanding would be better and our stress level would be lower. I smoked more to cope with the stress (Mohammed).

This from a second participant:

[T] here is no doubt that studying nursing at the university level was stressful and exhausting.... Maybe you [first author] had a similar experience to mine - there were clinical and theoretical days that I had to attend, scenario based assignments and exam questions [very difficult], I had to write a clinical report although I discussed the case verbally with the instructor, then: weekly care plans, post clinical conferences, seminars.... The other problem was that the clinical practice settings were not prepared for education. They lacked computers and Internet, data projectors, printers.... All stressors that I mentioned put me under tension until I finished the program, so I smoked more to reduce the stress level (Mustafa).

A third participant said:

I enjoyed studying nursing, I know many nursing students were struggling, but for me I found the nursing program was challenging but at the same time an interesting specialty. It was interesting to learn how to be a highly professional nurse, leader, and change agent. I enjoyed the nursing program because I was thinking of nursing as a lifestyle not only as a profession.... Yeah, but... each specialty has its stressors.... I faced two stressors that increased my smoking at university. I was upset when I saw university educated nurses working in a different way to how we were taught.... I thought those nurses were far from ideal, but look at me now. I work like them because the workplace climate forces nurses to just get the tasks done as quickly as possible. The second stressor was the lack of effective communication between nursing students and their professors and clinical instructors. Most nursing professors were aloof and put barriers between themselves and their students, so students could not discuss exams and marks with them. Clinical instructors controlled us by using threatening language; they threatened that they would give us a zero evaluation if we were late or did not do assignments... I became a regular smoker, just to buffer the stressors I faced (Ismael).

\section{Encouragement from Other Students.}

The participants who became regular smokers at university were encouraged to smoke when they found other students, including medical students, smoking on campus and no one said anything. One participant stated:

The first time I went to the university to register for the nursing program was two weeks before the fall term. During that short visit, I did not see many people smoking. I found "no smoking" and "smoke free university" signs everywhere. So my first impression was that smoking was not allowed. I decided to smoke off campus... but during the first two months of the fall term, I started to see students smoking everywhere and no one stopped them... I knew many friends who studied nursing were smoking while standing next to "smoke free zone" signs... Then I realized that smoking prohibition signs at the university were only for decoration .... I changed my thoughts and I smoked everywhere on campus and also in clinical training settings (outside buildings and in the cafeteria) (Yasser).

Another participant stated that although his smoking increased at university due to the influence of other smokers, he kept this hidden from the professors:

At the beginning, I drew an ideal image of what a nursing student must be.... I could not imagine myself smoking inside the nursing building.... I remember that my smoking increased when I was at university because I found students around me smoked freely... 
Guess what? I was smoking anywhere but near the nursing faculty because I did not want my professors to see me smoking.... Although smoking was normal in the medical faculty, including in the offices of professors and administrators, I hid my smoking from my professors because I did not want them to change their good opinion of me (Osama).

\section{Lax Enforcement of University Non-Smoking Policies}

There are smoking bans at Jordanian universities and even fines for those who break the no smoking rule, but the authorities do not enforce these by-laws. Furthermore, some students may not know there is a no-smoking policy.

One participant explained:

... Ah...um...I am not sure if there were smoking prohibition laws at the university where I studied ...but I am sure that I never heard about any prohibition on campus.... During the four years of nursing studies, I smoked in most places at the university but no one told me not to or asked me to stop.... I continued smoking and never felt anxious about what I was doing. But, now I'm wondering, why no one enforced the no-smoking law if there was one... (Ismael).

Another participant was more informed:

... Actually I was a member of the students' union and the health club at the university.... I know that all universities in Jordan have a smoking policy and other substance use prohibitions .... These laws were not optional because they were issued from the Jordan Ministry of Higher Education... and you can find detailed written policies regarding smoking on campus and the penalties for not observing the rules. But there was nothing about intervention. When I took the community health nursing course, I got more information about smoking products and ingredients, diseases caused by smoking, and some statistics but we had never been tanght treatment and/or protocols regarding smoking cessation. If we had learned something like that, at least we could help ourselves and our patients to stop smoking.... For your information, my brother is studying medicine, and nothing has been mentioned in his curriculum about smoking cessation protocols or unhealthy behaviours.... Currently, I am a first year master's student at the university I attended as an undergraduate. I do not see anything has changed regarding smoking policy on campus. Even in my master's program curriculum, I do not find special material about smoking assessment and intervention... What I really notice is that the number of smokers at the university is increasing. After my experience as a nurse who smokes, I would like to invite decision makers at health faculties to include health promotion-smoking cessation programs in the nursing curriculum (Kamal).

\section{Discussion}

The becoming a regular smoker phase in our contextualizing smoking behaviour over time theory is similar to the 'action stage' in the trans-theoretical model of smoking behaviours (DiClemente, 2003). According to DiClemente (2003), "once [a] new behaviour pattern is established in the routine of the individual, the task of behavioural change shifts to one of continuing the change over the long haul" ( p. 29). However, in the addiction literature, the definition of regular smoker has varied from one study to another. Commonly regular smoker is defined by the number of cigarettes smoked per day, such as smoking 15-24 cigarettes a day in a regular pattern (Wilson, Parsons, \& Wakefield, 1999).

In this study, the participants defined themselves as regular smokers when they started buying whole packs of cigarettes and began smoking around 14 cigarettes per day.

A lot is still unknown about how male Jordanian psychiatric nurses become regular smokers. What is clear from the experiences of our participants is that the time at university is an important period in the transition to regular smoking. This is not to say that the participants would not have become regular smokers if they had not attended university. Participation in age appropriate activities at home and at work is just as capable of promoting the transition from occasional smoker to regular smoker. The crucial contextualizing factors involved at what in grounded theory research is called the formal level of explanation (Glaser \& Strauss, 1967) are stressors associated with significant role transitions during the period of late adolescence and early adulthood; institutionalized failure to implement and enforce non-smoking policies; lack of information about and access to smoking cessation programs, and lack of familiarity with self-directed smoking cessation techniques. However, the transition from adolescence to adulthood is fundamental to becoming a regular smoker irrespective of whether contextual factors that enable smoking are experienced on entering university, taking a job, joining the military or remaining unemployed.

Our substantive findings confirm those of previous studies. Tucker, Ellickson, and Klein (2003) found that the transition from experimentation with cigarettes to regular patterns of smoking is influenced by positive societal attitudes and beliefs about smoking, smoking by peer group members, loss of parental control and support, and academic experiences 
that result in stress. Mao et al. (2009) found that: male gender, low family socioeconomic status, positive perceptions of peer smoking, perceived benefits of smoking, higher levels of pro-smoking attitudes, and higher levels of perceived social costs of non-smoking are associated with regular smoking.

Our findings support DiClemente's (2003) insistence on understanding changes in behaviour in the context of significant factors that facilitate or hinder change: the life situation; beliefs and attitudes; interpersonal relationships; and social systems:

- "The life situation" - For male Jordanian psychiatric nurses, the interrelated transition from adolescence to adulthood and from high school student to university nursing student is foundational to becoming a regular smoker.

- "Beliefs and attitudes" new meanings are deeply implicated in the transition to regular smoking. For example, at the beginning of the smoking journey, the meaning given to smoking by one participant was that it "gives me a feeling and image that I am mature and a real man" (Hassan). Later the meaning of smoking for this participant changed to regarding smoking as a way of relieving stress.

- "Interpersonal relationships" - The participants reported that ties to parents and family members changed as they transitioned into the life of a university student living among peers. Furthermore, the relationships newly formed with university teachers encouraged covert smoking, while those that developed with other students supported the transition to regular smoking.

- "Social systems" - The social system of the university and the norms of university campus supported the transition to regular smoking. University staff were seen to smoke on campus although smoking on campus was prohibited by law; no one enforced the smoking prohibition laws; smoking policies were not enforced; smoking cessation programs were not available; nursing curricular were devoid of content that might have helped students resist becoming regular smokers.

Our findings add descriptive detail to those reported by Haddad and Malak (2002). Student smokers in their study had positive attitudes and beliefs about smoking; they interacted regularly with other smokers, both faculty and students; there were no on-campus smoking restrictions; there was no access to smoking cessation programs; no time for regular exercise; and no access to alternative coping strategies that could reduce the stress of being away from home while experiencing the difficult transition from adolescence to adulthood.

The specific stressors male Jordanian psychiatric nurses coped with by smoking when they were students can be readily summarized:(a) a very broad (comprehensive) nursing curriculum with demanding time pressures, (b) miscommunication among nursing faculties and other faculties about program requirements, (c) high frequency of examinations and assignments, (d) the gap between what nursing students are taught and nursing practice, (e) lack of learning resources in clinical settings, and (f) lack of smoking cessation content in nursing curricula.

\section{Conclusion}

Our findings contribute to a deeper understanding of how contextual factors in Jordanian universities and faculties of nursing influence male psychiatric nurses to become regular smokers when they were students. The contextual factors we have described are significant in influencing male nursing students to transition from occasional to regular smoking. These factors have a strong influence because they reinforce male cultural stereotypes and are not moderated by access to resources to reduce or stop smoking. Although smoking among nursing students has been reported in many previous studies, the findings of our study are context specific. Therefore, they provide a basis for the Jordanian Ministry of Health, Jordanian university administrations; nurse faculty members and health promotion specialists to develop smoking prevention programs and smoking cessation programs to assist students. Such programs have potential to benefit both male nursing students and future users of inpatient psychiatric services in Jordan.

\section{REFERENCES}

[1] Aldiabat, K., \& Clinton, M. (2012). Contextualizing smoking behaviour over time: A smoking journey from pleasuring to suffering. Turkish Online Journal of Qualitative Inquiry, 3(1), 1-19.

[2] Baron-Epel, O. , Josephsohn, K., \& Ehrenfeld, M. (2004). Nursing students' perceptions of smoking prevention. Nurse Education Today, 24 (2), 145-151.doi:10.1016/j.nedt.2003.1 1.001

[3] Center for Disease Control and Prevention. (2002). Prevalence of selected risk factors for chronic disease Jordan. Retrieved from http://www.cdc.gov/od/oc/media /mmwrnews /n031031.htm.

[4] Clark, E., McCann, T. V., Rowe, K., \& Lazenbatt, A. (2004). Cognitive dissonance and undergraduate nursing students' knowledge of, and attitudes about, smoking.Journal of Advanced Nursing, 46, 586-594. doi:10.1111/j.13652648.20 04.03049.x

[5] DiClemente, C. (2003). Addiction and change: How addictions develop and addicted people recover. New York: Guilford Press.

[6] Durkin, A. (2007). Promoting smoking cessation among nursing students: How faculty can help? Nursing Education Perspectives, 28 (3), 150-154.

[7] Glaser, B., \& Strauss, A.(1967). The Discovery of Grounded 
Theory: Strategies for Qualitative Research. Chicago: Aldine.

[8] Haddad, L., \& Malak, M. (2002). Smoking habits and attitudes towards smoking among university students in Jordan. International Nursing Studies,39, 793-796. doi:10.1016/S0020-7489(02)00016-0

[9] Hammond, D., Tremblay, I., Chaiton, M., Lessard, E., \& Callard, C. (2005). Tobacco on campus: Industry marketing and tobacco control policy among post-secondary institutions in Canada. Tobacco Control, 14 136-140.doi:10.1136/tc.2004.009753

[10] Jordan Department of Statistics. (2006). Kingdom indicators. Retrieved from http://www.dos.gov.jo/sdb_pop/sdb_pop_a/indec_a.pdf

[11] Jordan Department of Statistics. (2002). Population-based survey. Retrieved from http://www.dos.gov.jo/dos home_a/main/index.htm

[12] Khader, Y. S., \& Alsadi, A. A. (2008). Smoking habits among university students in Jordon: Prevalence and associated factors. Eastern Mediterranean Health Journal,14 (4), 897-904.

[13] Kofahi, M., \& Haddad, L. (2005). Perception of lung cancer and smoking among college students in Jordan. Journal of Transcultural Nursing, 16(3), 245-254.doi:10.1177/1043659 605274830

[14] Lincoln, Y.S. \& Guba, E.G. (1985) Naturalistic inquiry. Newbury Park, Ca: Sage Publications.

[15] Ma'ayeh, S. (2003, January). “Jordan: Mass media campaign combating smoking requires serious commitment and not just words". WHO Tobacco Control Papers, Center for
Tobacco Control Research and Education, UC San Francisco. Retrieved fromhttp://escholarship.org/uc/item/1cd712m7?qu ery=Ma'ayeh\#page-3

[16] Mansour, A., Halabi, J., \& Dawani, H. (2009). Depression, hostility, and substance use among university students in Jordan. Mental Health and Substance Use, 2 (1), 52-63.

[17] Mao, R., Li, X., Stanton, B., Wang, J., Hong, Y., Zhang, H., \& Chen, X. (2009). Psychosocial correlates of cigarette smoking among college students in China. Health Education Research, 24 (1), 105-118. doi: 10.1093/her/cyn002

[18] Smith, D. ( 2007). A systematic review of tobacco smoking among nursing students. Nurse Education in Practice,7, 293-302. doi: 10.1016/j.nepr.2006.09.003

[19] Suzuki, K., Ohida, T. Yokoyama, E. Kaneita, Y., \& Takemura, S. (2005). Smoking among Japanese nursing students: Nationwide survey. Journal of Advanced Nursing,49(3),268-275.doi:10.1111/j.1365-2648.2004.03291 . $\mathrm{x}$

[20] Tucker, J. S., Ellickson, P. L., \& Klein, D. J. (2003). Predictors of the transition to regular smoking during adolescence and young adulthood. Journal of Adolescent Health, 32 (4), 314-324. doi: 10.1016/S1054-139X(02)00709-7

[21] Wilson, D., Parsons, J., \& Wakefield, M. (1999). The health-related quality - of- life of never smokers, ex-smokers, and light, moderate, and heavy smokers. Preventive Medicine, 29,139-144. doi: 10.1006/pmed.1999.0523

[22] World Health Organization [WHO] . (1997). Plan of action for tobacco control in the Eastern Mediterranean region. Eastern Mediterranean Health Journal, 3 (1), 168-175. 